\title{
PERSPECTIVE
}

\section{Viruses and the origin of microbiome selection and immunity}

\author{
Steven D Quistad ${ }^{1,2,3}$, Juris A Grasis ${ }^{1}$, Jeremy J Barr ${ }^{1,4}$ and Forest L Rohwer ${ }^{1}$ \\ ${ }^{1}$ Department of Biology, San Diego State University, San Diego, CA, USA; ${ }^{2}$ Laboratoire de Colloïdes et \\ Matériaux Divisés (LCMD), Institute of Chemistry, Biology, and Innovation, ESPCI ParisTech/CNRS UMR \\ 8231/PSL Research University, Paris, France; ${ }^{3}$ Laboratoire de Colloïdes et Matériaux Divisés (LCMD), Institute \\ of Chemistry, Biology, and Innovation, ESPCI ParisTech/CNRS UMR 8231/PSL Research University, Paris, \\ France and ${ }^{4}$ School of Biological Sciences, Monash University, Clayton, Victoria 3800, Australia
}

\begin{abstract}
The last common metazoan ancestor (LCMA) emerged over half a billion years ago. These complex metazoans provided newly available niche space for viruses and microbes. Modern day contemporaries, such as cnidarians, suggest that the LCMA consisted of two cell layers: a basal endoderm and a mucus-secreting ectoderm, which formed a surface mucus layer (SML). Here we propose a model for the origin of metazoan immunity based on external and internal microbial selection mechanisms. In this model, the SML concentrated bacteria and their associated viruses (phage) through physical dynamics (that is, the slower flow fields near a diffusive boundary layer), which selected for mucin-binding capabilities. The concentration of phage within the SML provided the LCMA with an external microbial selective described by the bacteriophage adherence to mucus (BAM) model. In the BAM model, phage adhere to mucus protecting the metazoan host against invading, potentially pathogenic bacteria. The same fluid dynamics that concentrated phage and bacteria in the SML also concentrated eukaryotic viruses. As eukaryotic viruses competed for host intracellular niche space, those viruses that provided the LCMA with immune protection were maintained. If a resident virus became pathogenic or if a non-beneficial infection occurred, we propose that tumor necrosis factor (TNF)-mediated programmed cell death, as well as other apoptosis mechanisms, were utilized to remove virally infected cells. The ubiquity of the mucosal environment across metazoan phyla suggest that both BAM and TNF-induced apoptosis emerged during the Precambrian era and continue to drive the evolution of metazoan immunity.
\end{abstract}

The ISME Journal (2017) 11, 835-840; doi:10.1038/ismej.2016.182; published online 16 December 2016

\section{Introduction}

Microbial selectives

Most immune components have been discovered within the context of pathogenesis (Tanji and Ip, 2005; Kawai and Akira, 2010). This emphasis has led to the implicit assumption that immunology is the study of host versus pathogen (Casadevall and Pirofski, 2014). This two-dimensional bias is exemplified through the pervasive use of antimicrobial when describing host-microbe interactions (Brogden, 2005; Casadevall and Pirofski, 2014). In nature, host-pathogen interactions occur within the context of an ecological community, that is, a host in symbiosis with its microbial partners, which is called the holobiont (Casadevall and Pirofski, 2014; Bordenstein and Theis, 2015). These symbioses run

Correspondence: S Quistad, Institute of Chemistry, Biology, and Innovation, ESPCI ParisTech, 10 Rue Vauquelin, Paris 75005, France.

E-mail: steven.quistad@gmail.com

Received 25 May 2016; revised 15 September 2016; accepted 10 November 2016; published online 16 December 2016 the gamut of mutualistic to parasitic/pathogenic. Niche exclusion is an essential dynamic for maintaining the holobiont; any microbe, compound or entity that removes a microbe from a particular ecosystem creates novel niche space for another microbe to occupy (Rodriguez-Brito et al., 2010). In this perspective, we will utilize the term microbial selective to describe mechanisms that maintain specific microbes associated with a metazoan host.

The ever-changing, ubiquitous surface mucus layer (SML)

Mucosal environments coat the surfaces of specific epithelial cell types across the spectrum of metazoan life (Bäckhed et al., 2005; Brown and Bythell, 2005). These environments are constructed by mucin macromolecules, which consist of a peptide backbone covalently bonded to variable oligosaccaride side chains (Ferez-Vilar and Hill, 1999; Hang and Bertozzi, 2005; Corfield, 2013). The process of glycosylation is controlled by secondary structural motifs (Julenius et al., 2005), the cellular repertoire 
of glycosyltransferases and their localization within the Golgi apparatus resulting in distinct cellular profiles (Hanisch, 2001). O-linked glycosylation has been shown to be integral in immune protection across the animal phyla (Tsuboi and Fukuda, 2001; Bond et al., 2014). Following posttranslational modification, mucins are either tethered to the epithelial cell surface or secreted into the surrounding environment forming the SML. Molecular interactions between mucin molecules via hydrophobic cysteine-rich domains (Silberberg and Meyer, 1982; Bansil et al., 1995) and the formation of disulfide bonds (Roberts, 1976) results in a viscoeleastic material that provides the host with a physiochemical barrier from the surrounding environment (Gendler and Spicer, 1995; Johansson et al., 2013). In addition to providing the host with protection, the SML also concentrates particles from the environment by providing a smooth layer that encourages laminar (versus turbulent) flow, thereby creating an effective particle trap (Wild et al., 2004; Yang et al., 2012; Hill et al., 2014). There is significant turnover of the SML; the mouse gastrointestinal tract is capable of replacing its entire mucin pool in a single day (Faure et al., 2002) and corals release up to $4.8 \mathrm{l}$ of mucus per square meter of reef per day (Wild et al., 2004).

\section{Microbes and viruses in the SML}

Despite the high turnover, the SML is inhabited by a diverse and stable assemblage of microbes and their associated viruses, forming the SML microbiome (Bäckhed et al., 2005; Lozupone et al., 2012; Schluter and Foster, 2012; Closek et al., 2014). Individual members of the SML microbiome gain access to energy-rich mucins (Derrien et al., 2010) while providing the metazoan host with a variety of benefits, including immune protection (Cash and Hooper, 2005; Sun and Chang, 2014) and nutrient production (Thompson et al., 2015). Here we focus on SMLassociated bacteria and their predators, bacteriophage (a.k.a. phage). To ensure retention within the SML, bacteria and phage have evolved mucus-binding proteins capable of responding to rapid environmental change. For example, Lactobacillus sp. express a range of proteins containing mucus-binding domains that exhibit high genetic heterogeneity between strains, suggesting they are adaptive (MacKenzie et al., 2010). Similarly, T4 phage use the immunoglobulin-like (Ig-like) domains of their capsid proteins to promote mucus adherence. (Fraser et al., 2006; Barr et al., 2013). Ig-like domains and related protein folds, such as C-type lectins, contain variable regions, potentially allowing phage to adapt to changes in the mucin pool and maintain specific phage-metazoan associations (Minot et al., 2012; Barr et al., 2013).

Phage drive bacterial evolution

Within the SML, phage outnumber their bacterial hosts by roughly an order of magnitude (Barr et al.,
2013). Upon infection, phage replicate via either lytic or lysogenic life cycles. The lytic cycle involves the production of new virus particles, ultimately leading to cell lysis and viral release. Alternatively, in the lysogenic cycle the phage genome integrates into the host genome and becomes a prophage. Temperate phage utilize both lytic and lysogenic strategies and are important drivers of evolution in the SML (De Paepe et al., 2016). Depending on the genetic repertoire of the newly acquired prophage, bacterial physiology can be directly affected through the donation of novel genes, disruption of host genes and manipulation of cellular metabolism (Brüssow et al., 2004). In addition, some temperate phage provide their host with immune protection by preventing the attachment of other phage particles (superinfection exclusion) (Soller and Epstein, 1965) or preventing phage propagation of a secondary infection (superinfection immunity) (West and Scott, 1977; Fogg et al., 2010; Abedon, 2015). These mutualistic temperate phage enhance the competitive fitness of their hosts (Bossi et al., 2003) and drive bacterial evolution (Obeng et al., 2016).

\section{Discussion}

Colonization of the SML in the last common metazoan ancestor (LCMA)

Fossil evidence and molecular data suggest the LCMA emerged sometime between the Cryogenian and Ediacaran periods approximately 542-720 million years ago (Davidson and Erwin, 2009). The LCMA most likely consisted of two cell layers: an ectoderm with a SML and an internally facing endoderm (Müller, 2003; Lang et al., 2007). We propose that the first bacteria arrived to the SML through active chemotaxis toward energy-rich mucins (Bansil et al., 1995; Stocker and Seymour, 2012), random sequestration by SML fluid dynamics (Wild et al., 2004; Yang et al., 2012; Hill et al., 2014) or both. The dynamic properties of the SML would have selected for bacteria that could be maintained through the expression of mucus-binding proteins or similar mucus-binding mechanisms (MacKenzie et al., 2010). Once established within the SML, bacteria that provided the metazoan host with a fitness advantage via competitive exclusion of potential pathogens or nutrient production would have been further selected. The arrival of the first phage may have occurred in conjunction with the first bacteria as an integrated prophage or from the environment as a temperate/lytic phage. Prophage associated with the first bacterial colonizers increased host fitness through superinfection exclusion and superinfection immunity mechanisms (Soller and Epstein, 1965; Abedon, 2015). As the first bacterial species continued to propogate, phage capable of binding to mucins (for example, Ig-like domains, among others) were favored by natural selection. Colonization by additional bacterial 
species and their associated phage continued in the SML until niche space was filled and a community was formed. Mutualistic bacteria continued to protect the metazoan host through competitive exclusion of potential pathogens (Hibbing et al., 2010) while phage provided immune protection as proposed in the bacteriophage adherence to mucus (BAM) model (Barr et al., 2013, 2015). In the BAM model, phage adhering to mucus provide the host with immune protection against invading pathogens (Figure 1a). For an in depth discussion of where competitive exclusion and lytic dynamics are operating within the SML, the authors point the reader to the following article (Silveira and Rohwer, 2016).

Tumor necrosis factor (TNF)-induced apoptosis—an internal microbial selective

Although the colonization of the SML by specific phage species provided the metazoan host with immune protection, the same fluid dynamics also increased the retention of eukaryotic viruses and subsequent adsorption to the LCMA host. As with

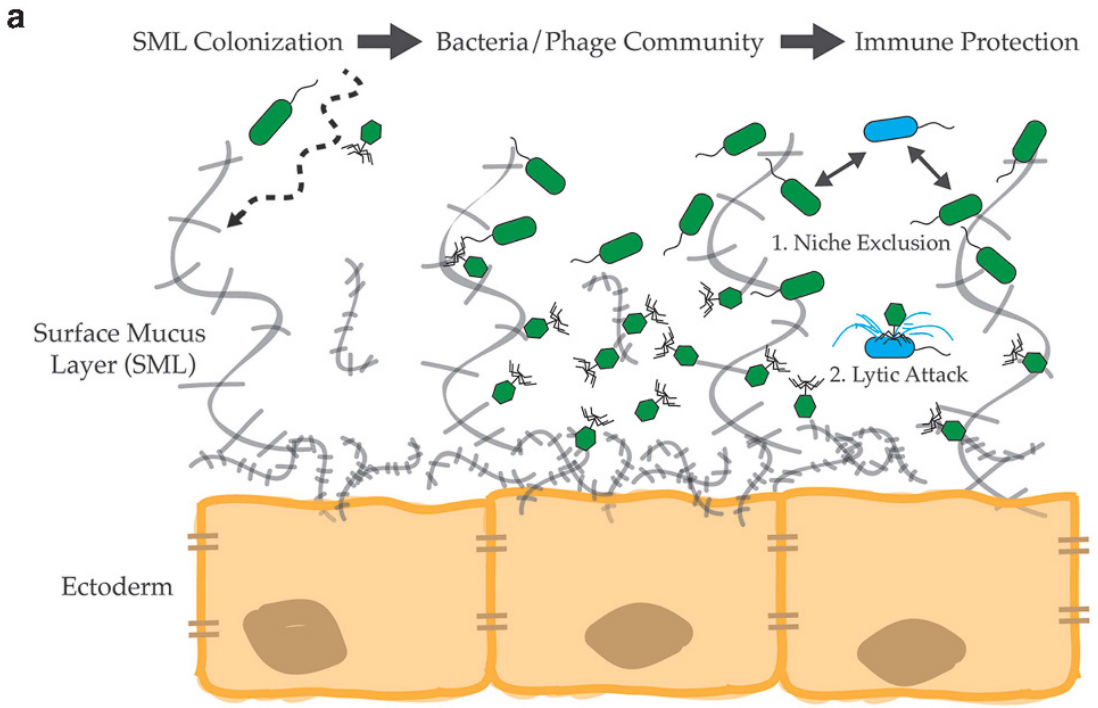

b

1) Increased Contact with Eukaryotic Viruses

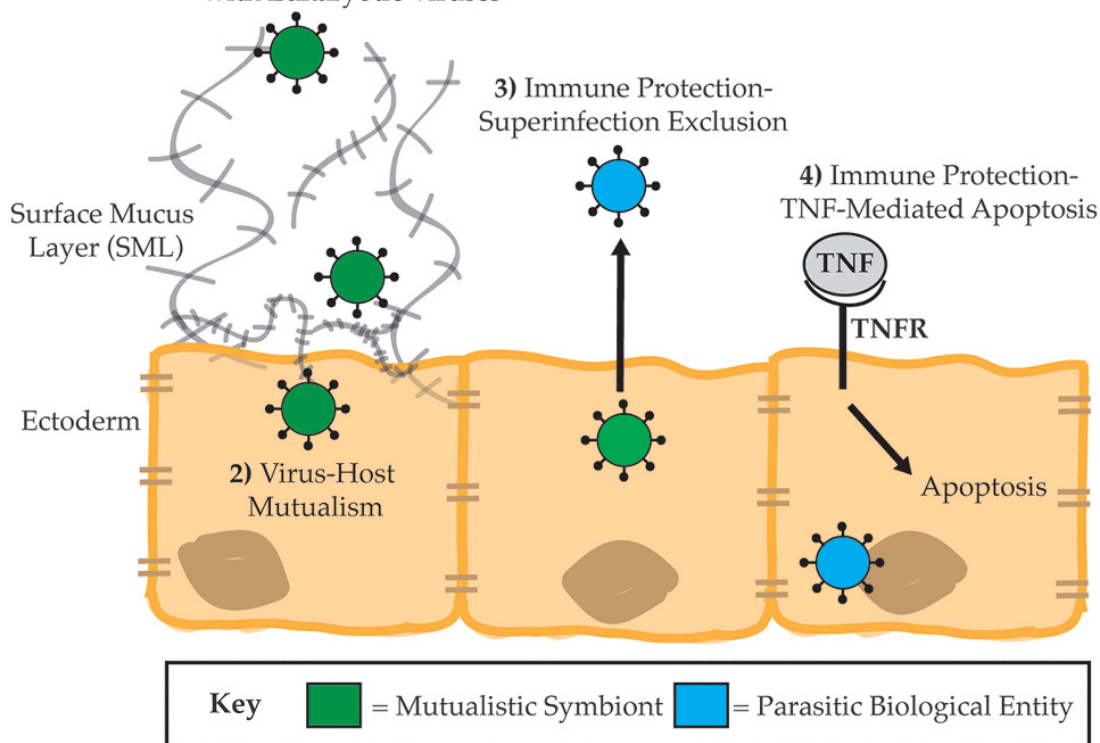

Figure 1 Microbial selective mechanisms in the LCMA. (a) BAM. Energy-rich mucin macromolecules secreted from the ectoderm formed a SML that was colonized by bacteria and associated phage. Mutualistic phage provided the LCMA with immune protection from invading bacteria via (1) competitive exclusion and (2) lytic attack. (b) TNF-mediated apoptosis. Mucins also increased the rate of contact between eukaryotic viruses and their metazoan hosts leading to the formation of mutualistic relationships. Viruses that provided the LCMA host with immune protection were maintained. If a beneficial virus became pathogenic or if a parasitic virus invaded, the infected cell was removed via TNF-mediated apoptosis and other apoptotic mechanisms. 
the phage, these eukaryotic viruses developed mechanisms to bind to mucins and infect host cells (for example, influenza virus today; Wild et al., 2004). Upon infection of a multicellular host, the canonical response is programmed cell death or apoptosis of the infected cell, thus preventing viral dissemination to neighboring cells (Barber, 2001). Apoptosis has been observed across the spectrum of life from bacteria to animals (Lewis, 2000; Bidle et al., 2007). Many versions of apoptosis exist (Holler et al., 2000; Berg et al., 2001; Bratosin et al., 2001) and the general process likely emerged with the origin of multicellularity (Ellis and Horvitz, 1986; Raff, 1992; Steller, 1995; Aravind et al., 2001). However, metazoan apoptosis appears to be unique through its use of TNF receptors (Quistad and Traylor-Knowles, 2016), which are activated by TNF ligands (Aggarwal, 2003). Many of the domains involved with apoptotic signaling via TNF receptors are also present and functional in cnidarians, considered to be among the oldest animal phyla (Lasi et al., 2010; Quistad et al., 2014; Sakamaki et al., 2014, 2015; Lu et al., 2016; Moya et al., 2016).

The targeted destruction of a virally infected cell is the most conservative approach to maintain organismal integrity; however, viruses can also provide the host with a selective advantage. For example, Herpesviruses provide mice with protection from bacterial infection (Barton et al., 2007) and latent dynamics with Herpesviruses and their metazoan hosts have been described from cnidarians (Vega Thurber et al., 2008; Grasis et al., 2014) to humans, suggesting an ancient origin (Steiner, 1996). In addition, similar to temperate phage, metazoan viruses provide their hosts with immune protection via superinfection exclusion (Tscherne et al., 2007; Zou et al., 2009). If the beneficial virus or virally encoded element is transferred to the germline through reverse transcription (RNA viruses) or recombination (DNA viruses), then the trait could be inherited by future generations and drive evolutionary processes (for example, endogenous retroviruses) (Grow et al., 2015). Evidence for past viral co-option events can be found throughout the modern metazoan immune system (Villarreal, 2011) including the canonical response to viral infection: interferon production (Chuong et al., 2016).

We propose that competition between viruses for host niche space led to the formation of mutualistic relationships between the LCMA and its resident viruses. Those associations that provided the host with immune protection were maintained. In those cases where resident viruses were not protective or they developed into a pathogenic infection, the LCMA removed the infected cell via TNF-mediated apoptosis, among other apoptotic mechanisms (Figure 1b). Based on extant animal phyla, the LCMA possessed a large and dynamic stem cell population (Bosch, 2009), therefore, it could rapidly replace any cells deemed to be a risk to organismal integrity without incurring a major fitness cost. Taken together, TNF receptors served as the viral gatekeepers to the LCMA, promoting beneficial chronic infections and eliminating destructive interactions.

\section{Conclusions}

Here we have proposed a model for the development of metazoan immunity via external (phage) and internal (TNF-mediated apoptosis) microbial selective mechanisms. The LCMA secreted mucins from epithelial tissue, generating an SML that selected for bacteria and phage with mucin-binding properties. Phage provided the LCMA with an external microbial selective in which phage bound to mucus via hypervariable domains protect the metazoan host from invading bacteria (BAM) (Barr et al., 2013, 2015). In addition to attracting bacteria and phage, mucins also increased the rate of contact with eukaryotic viruses resulting in the development of mutualistic symbiosis that provided the LCMA with immune protection. If a new virus was pathogenic or if a resident virus became parasitic, those cells were eliminated via TNF-mediated apoptosis and other versions of apoptosis. We hypothesize that both microbial selective mechanisms described here evolved during the Precambrian era and continue to drive the evolution of metazoan immunity in modern day phyla.

\section{Conflict of Interest}

The authors declare no conflict of interest.

\section{References}

Abedon ST. (2015). Bacteriophage secondary infection. Virol Sin 30: 3-10.

Aggarwal BB. (2003). Signalling pathways of the TNF superfamily: a double-edged sword. Nat Rev Immunol 3: $745-756$.

Aravind L, Dixit VM, Koonin EV. (2001). Apoptotic molecular machinery: vastly increased complexity in vertebrates revealed by genome comparisons. Science 291: 1279-1284.

Bäckhed F, Ley RE, Sonnenburg JL, Peterson Da, Gordon JI. (2005). Host-bacterial mutualism in the human intestine. Science 307: 1915-1920.

Bansil R, Stanley E, LaMont JT. (1995). Mucin biophysics. Annu Rev Physiol 57: 635-657.

Barber GN. (2001). Host defense, viruses and apoptosis. Cell Death Differ 8: 113-126.

Barr JJ, Auro R, Furlan M, Whiteson KL, Erb ML, Pogliano J et al. (2013). Bacteriophage adhering to mucus provide a non-host-derived immunity. Proc Natl Acad Sci USA 110: 10771-10776. 
Barr JJ, Auro R, Sam-Soon N, Kassegne S, Peters G, Bonilla N et al. (2015). Subdiffusive motion of bacteriophage in mucosal surfaces increases the frequency of bacterial encounters. Proc Natl Acad Sci 112: 13675-13680.

Barton ES, White DW, Cathelyn JS, Brett-McClellan Ka, Engle M, Diamond MS et al. (2007). Herpesvirus latency confers symbiotic protection from bacterial infection. Nature 447: 326-329.

Berg CP, Engels IH, Rothbart A, Lauber K, Renz A, Schlosser SF et al. (2001). Human mature red blood cells express caspase-3 and caspase-8, but are devoid of mitochondrial regulators of apoptosis. Cell Death Differ 8: 1197-1206.

Bidle KD, Haramaty L, Barcelos E, Ramos J, Falkowski P. (2007). Viral activation and recruitment of metacaspases in the unicellular coccolithophore, Emiliania huxleyi. Proc Natl Acad Sci USA 104: 6049-6054.

Bond MR, Ghosh SK, Wang P, Hanover JA. (2014). Conserved nutrient sensor O-GlcNAc transferase is integral to $C$. elegans pathogen-specific immunity. PLoS One 9: e113231.

Bordenstein SR, Theis KR. (2015). Host biology in light of the microbiome: ten principles of holobionts and hologenomes. PLoS Biol 13: e1002226.

Bosch TCG. (2009). Hydra and the evolution of stem cells. Bioessays 31: 478-486.

Bossi L, Fuentes JA, Mora G, Figueroa-Bossi N. (2003). Prophage contribution to bacterial population dynamics. J Bacteriol 185: 6467-6471.

Bratosin D, Estaquier J, Petit F, Arnoult D, Quatannens B, Tissier JP et al. (2001). Programmed cell death in mature erythrocytes: a model for investigating death effector pathways operating in the absence of mitochondria. Cell Death Differ 8: 1143-1156.

Brogden KA. (2005). Antimicrobial peptides: pore formers or metabolic inhibitors in bacteria? Nat Rev Microbiol 3: 238-250.

Brown BE, Bythell JC. (2005). Perspectives on mucus secretion in reef corals. Mar Ecol Prog Ser 296: 291-309.

Brüssow H, Canchaya C, Hardt W-D. (2004). Phages and the evolution of bacterial pathogens: from genomic rearrangements to lysogenic conversion. Microbiol Mol Biol Rev 68: 560-602 table of contents.

Casadevall A, Pirofski LA. (2014). Ditch the term pathogen. Nature 516: 165-166.

Cash HL, Hooper LV. (2005). Commensal bacteria shape intestinal immune system development. ASM News 71: 77-83.

Chuong EB, Elde NC, Feschotte C. (2016). Regulatory evolution of innate immunity through co-option of endogenous retroviruses. Science 351: 1083-1087.

Closek CJ, Sunagawa S, DeSalvo MK, Piceno YM, DeSantis TZ, Brodie EL et al. (2014). Coral transcriptome and bacterial community profiles reveal distinct Yellow Band Disease states in Orbicella faveolata. ISME J 8: 2411-2422.

Corfield AP. (2013). Mucins: a biologically relevant glycan barrier in mucosal protection. Biochim Biophys Acta 1850: 236-252.

Davidson EH, Erwin DH. (2009). An integrated view of precambrian eumetazoan evolution. Cold Spring Harb Symp Quant Biol 74: 65-80.

Derrien M, van Passel MW, van de Bovenkamp JH, Schipper RG, de Vos WM, Dekker J. (2010). Mucinbacterial interactions in the human oral cavity and digestive tract. Gut Microbes 1: 254-268.
Ellis HM, Horvitz HR. (1986). Genetic control of programmed cell death in the nematode $C$. elegans. Cell 44: 817-829.

Faure M, Moennoz D, Montigon F, Fay LB, Breulille D, Finot PA et al. (2002). Development of a rapid and convenient method to purify mucins and determine their in vivo synthesis rate in rats. Anal Biochem 307: 244-251.

Ferez-Vilar J, Hill RL. (1999). The structure and assembly of secreted mucins. J Biol Chem 274: 31751-31754.

Fogg PCM, Allison HE, Saunders JR, McCarthy AJ. (2010). Bacteriophage lambda: a paradigm revisited. J Virol 84: 6876-6879.

Fraser JS, Yu Z, Maxwell KL, Davidson AR. (2006). Ig-like domains on bacteriophages: a tale of promiscuity and deceit. J Mol Biol 359: 496-507.

Gendler SJ, Spicer AP. (1995). Epithelial mucin genes. Annu Rev Physiol 57: 607-634.

Grasis JA, Lachnit T, Anton-Erxleben F, Lim YW, Schmieder R, Fraune S et al. (2014). Species-specific viromes in the ancestral holobiont hydra. PLoS One 9: e109952.

Grow EJ, Flynn RA, Chavez SL, Bayless NL, Wossidlo M, Wesche DJ et al. (2015). Intrinsic retroviral reactivation in human preimplantation embryos and pluripotent cells. Nature 522: 221-225.

Hang HC, Bertozzi CR. (2005). The chemistry and biology of mucin-type O-linked glycosylation. Bioorganic Med Chem 13: 5021-5034.

Hanisch FG. (2001). O-glycosylation of the mucin type. Biol Chem 382: 143-149.

Hibbing ME, Fuqua C, Parsek MR, Peterson SB. (2010). Bacterial competition: surviving and thriving in the microbial jungle. Nat Rev Microbiol 8: 15-25.

Hill DB, Vasquez PA, Mellnik J, McKinley SA, Vose A, $\mathrm{Mu} \mathrm{F}$ et al. (2014). A biophysical basis for mucus solids concentration as a candidate biomarker for airways disease. PLoS One 9: e87681.

Holler N, Zaru R, Micheau O, Thome M, Attinger A, Valitutti $S$ et al. (2000). Fas triggers an alternative, caspase-8-independent cell death pathway using the kinase RIP as effector molecule. Nat Immunol 1: 489-495.

Johansson MEV, Sjövall H, Hansson GC. (2013). The gastrointestinal mucus system in health and disease. Nat Rev Gastroenterol Hepatol 10: 352-361.

Julenius K, Mølgaard A, Gupta R, Brunak S. (2005). Prediction, conservation analysis, and structural characterization of mammalian mucin-type O-glycosylation sites. Glycobiology 15: 153-164.

Kawai T, Akira S. (2010). The role of pattern-recognition receptors in innate immunity: update on Toll-like receptors. Nat Immunol 11: 373-384.

Lang T, Hansson GC, Samuelsson T. (2007). Gel-forming mucins appeared early in metazoan evolution. Proc Natl Acad Sci USA 104: 16209-16214.

Lasi M, David C, Böttger A. (2010). Apoptosis in preBilaterians: hydra as a model. Apoptosis 15: 269-278.

Lewis K. (2000). Programmed death in bacteria. Microbiol Mol Biol Rev 64: 503-514.

Lozupone CA, Stombaugh JI, Gordon JI, Jansson JK, Knight R. (2012). Diversity, stability and resilience of the human gut microbiota. Nature 489: 220-230.

Lu W, Chen Q, Ying S, Xia X, Yu Z, Lui Y et al. (2016). Evolutionarily conserved primary TNF sequences relate to its primitive functions in cell death induction. J Cell Sci 129: 108-120. 
MacKenzie DA, Jeffers F, Parker ML, Vibert-Vallet A, Bongaerts RJ, Roos S et al. (2010). Strain-specific diversity of mucus-binding proteins in the adhesion and aggregation properties of Lactobacillus reuteri. Microbiology 156: 3368-3378.

Minot S, Grunberg S, Wu GD, Lewis JD, Bushman FD. (2012). Hypervariable loci in the human gut virome. Proc Natl Acad Sci 109: 3962-3966.

Moya A, Sakamaki K, Mason BM, Huisman L, Forêt S, Weiss Y et al. (2016). Functional conservation of the apoptotic machinery from coral to man: the diverse and complex Bcl-2 and caspase repertoires of Acropora millepora. BMC Genomics 17: 1-20.

Müller WEG. (2003). The origin of metazoan complexity: porifera as integrated animals. Integr Comp Biol 43: 3-10.

Obeng N, Pratama AA, van Elsas J. (2016). The significance of mutualistic phages for bacterial ecology and evolution. Trends Microbiol 24: 440-449.

De Paepe M, Tournier L, Moncaut E, Son O, Langella P, Petit MA. (2016). Carriage of $\lambda$ latent virus is costly for its bacterial host due to frequent reactivation in monoxenic mouse intestine. PLoS Genet 12: e1005861.

Quistad SD, Stotland A, Barott KL, Smurthwaite CA, Hilton BJ, Grasis JA et al. (2014). Evolution of TNFinduced apoptosis reveals $550 \mathrm{My}$ of functional conservation. Proc Natl Acad Sci 111: 9567-9572.

Quistad SD, Traylor-Knowles N. (2016). Precambrian origins of the TNFR superfamily. Cell Death Discov 2: 16058.

Raff MC. (1992). Social controls on cell survival and cell death. Nature 356: 397-400.

Roberts GP. (1976). The role of disulfide bonds in maintaining the gel structure of bronchial mucus. Arch Biochem Biophys 173: 528-537.

Rodriguez-Brito B, Li L, Wegley L, Furlan M, Angly F, Breitbart $\mathrm{M}$ et al. (2010). Viral and microbial community dynamics in four aquatic environments. ISME J 4: 739-751.

Sakamaki K, Shimizu K, Iwata H, Imai K, Satou Y, Funayama $\mathrm{N}$ et al. (2014). The apoptotic initiator caspase-8: its functional ubiquity and genetic diversity during animal evolution. Mol Biol Evol 31: 3282-3301.

Schluter J, Foster KR. (2012). The evolution of mutualism in gut microbiota via host epithelial selection. PLOS Biol 10: e1001424.

Silberberg A, Meyer FA. (1982). Structure and function of mucus. Adv Exp Med Biol 144: 53-74.

Silveira CB, Rohwer FL. (2016). Piggyback-the-Winner in host-associated microbial communities. NPJ Biofilms Microbiomes 2: 16010.

Soller A, Epstein HT. (1965). Biochemical and immunological aspects of the exclusion of lambda by superinfection with T4. Virology 26: 715-726.
Steiner I. (1996). Human herpes viruses latent infection in the nervous system. Immunol Rev 152: 157-173.

Steller H. (1995). Mechanisms and genes of cellular suicide. Science 267: 1445-1449.

Stocker R, Seymour JR. (2012). Ecology and physics of bacterial chemotaxis in the ocean. Microbiol Mol Biol Rev 76: 792-812.

Sun J, Chang EB. (2014). Exploring gut microbes in human health and disease: pushing the envelope. Genes Dis 1: 132-139.

Tanji T, Ip YT. (2005). Regulators of the Toll and Imd pathways in the Drosophila innate immune response. Trends Immunol 26: 193-198.

Thompson JR, Rivera HE, Closek CJ, Medina M. (2015). Microbes in the coral holobiont: partners through evolution, development, and ecological interactions. Front Cell Infect Microbiol 4: 176.

Tscherne DM, Evans MJ, von Hahn T, Jones CT, Stamataki Z, McKeating JA et al. (2007). Superinfection exclusion in cells infected with hepatitis $\mathrm{C}$ virus. J Virol 81: 3693-3703.

Tsuboi S, Fukuda M. (2001). Roles of O-linked oligosaccharides in immune responses. BioEssays 23: 46-53.

Vega Thurber RL, Barott KL, Hall D, Liu H, RodriguezMueller B, Desnues C et al. (2008). Metagenomic analysis indicates that stressors induce production of herpes-like viruses in the coral Porites compressa. Proc Natl Acad Sci USA 105: 18413-18418.

Villarreal LP. (2011). Viral ancestors of antiviral systems. Viruses 3: 1933-1958.

West BW, Scott JR. (1977). Superinfection immunity and prophage repression in phage P1 and P7 III. Induction by virulent mutants. Virology 78: 267-276.

Wild C, Huettel M, Klueter A, Kremb SG, Rasheed MYM, Jørgensen BB. (2004). Coral mucus functions as an energy carrier and particle trap in the reef ecosystem. Nature 428: 66-70.

Yang X, Forier K, Steukers L, van Vlierberghe S, Dubruel P, Braeckmans K et al. (2012). Immobilization of pseudorabies virus in porcine tracheal respiratory mucus revealed by single particle tracking. PLoS One 7: e51054.

Zou G, Zhang B, Lim P-Y, Yuan Z, Bernard Ka, Shi P-Y. (2009). Exclusion of West Nile virus superinfection through RNA replication. J Virol 83: 11765-11776.

Sakamaki K, Imai K, Tomii K, Miller D. (2015). Evolutionary analyses of caspase-8 and its paralogs: deep origins of the apoptotic signaling pathways. Bioessays 37: 767-776. 